\title{
CHOROID PLEXUS PAPILLOMA OF THIRD VENTRICLE
}

\author{
(Case Report)
}

\author{
Lt Col PRAKASH SINGH ${ }^{*}$, Col AP SINGH ${ }^{+}$ \\ Lt Col SARV SARUP *, Lt Col VK BATISH , \\ Maj RAJESH KHANNA \#
}

MJAFI 1998; 54 : 360-362

KEY WORDS : Choroid plexus papilloma; Third ventricle; Micro surgical excision.

\section{Introduction}<smiles>[CH3]</smiles>

horoid plexus papillomas are rare tumours of the central nervous system, occurring with a relative incidence of about $0.6 \%$ of all intracranial tumours in adults and $3 \%$ in children $[1,2]$. They arise from the epithelium of the choroid plexus where so-ever it is found. In children they commonly occur in the lateral ventricles and in adults in the fourth ventricle [2] Choroid plexus papilloma rarely occurs in the third ventricle. In a review of literature by Gradin et al [3], only 19 cases were found. We are reporting another case of third ventricular choroid plexus papilloma in a two year old child.

\section{Case Report}

A two-year-old male child, born full term normal delivery, was noticed to have slightly delayed mile stones i.e. head holding at 6 months, speech at 15 months and walking with support at 18 months and subtle gradual enlargement of the head. There was no history of vomiting. Clinical examination revealed a healthy child. Vitals were normal. Occipito-frontal circumference was $52 \mathrm{cms}$. Neurologically except for bilateral papilloedema he had no focal motor or sensory deficit. Haematological and biochemical investigations were normal. X-ray skull did not reveal any abnormality. $A$ computerised tomography scan plain and contrast enhanced showed a large $(5 \times 4 \times 3.5 \mathrm{cms})$ third ventricular tumour with calcification (Fig.1) which enhanced diffusely and intensely with contrast and was well seen on coronal cuts (Fig. 2). He underwent transcallosal interforniceal microsurgical total excision of tumour. At surgery the tumour was greyish pink in colour, well encapsulated but had a cauli-flower like surface, solid in consistency and very vascular. Post operatively he had left hemiparesis which persisted even at 6 months after surgery. A repeat computerised tomography scan study after 3 weeks of surgery confirmed total excision of tumour (Fig. 3). Histopathology showed striking villous appearance with villi having a cuboidal epithelium on a fibrovascular core (Fig. 4). No mitosis or cellular pleomorphism were seen.

\section{Discussion}

. Of all the choroid plexus papillomas $43 \%$ are found

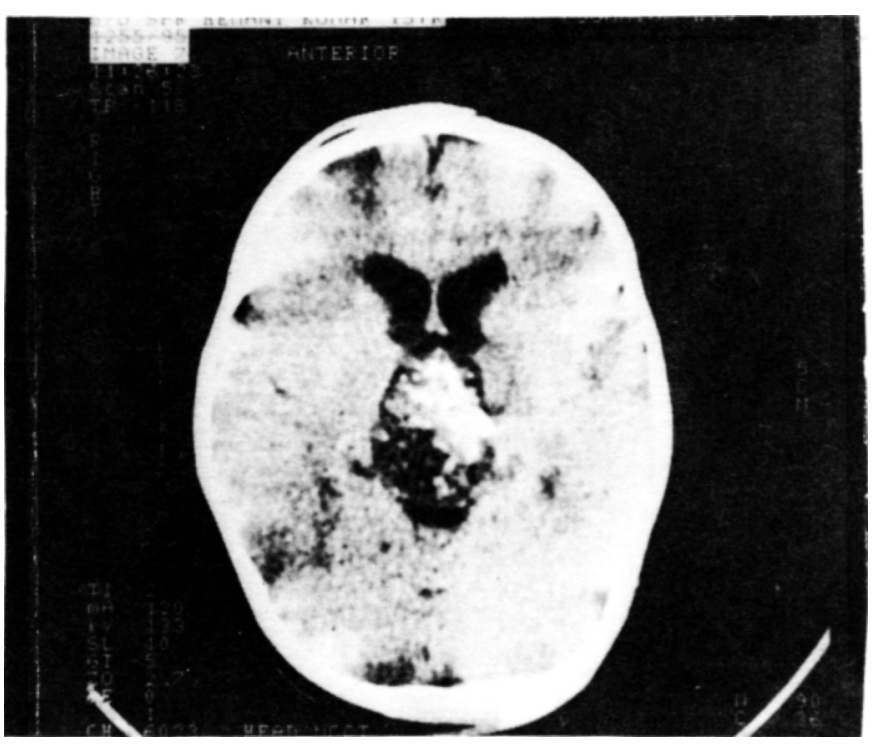

Fig. 1 : Non contrast CT scan shows a large 3rd ventricular tumour with calcification occupying the whole of $3 \mathrm{rd}$ ventricle. Mild hydrocephalus is also evident

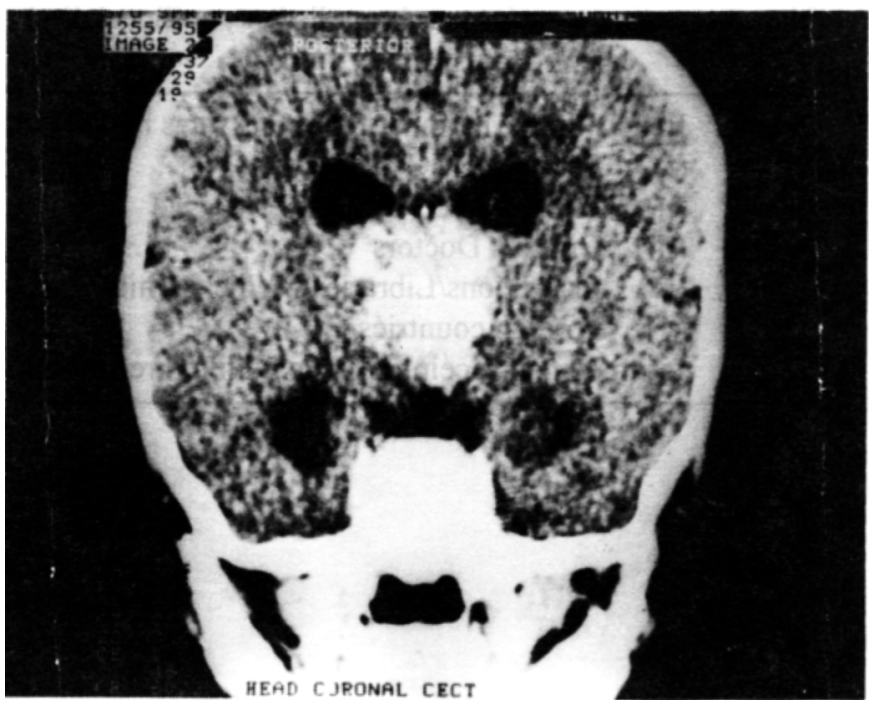

Fig. 2: Tumour seen in coronal cut shows vertical extent of the tumour

\footnotetext{
Classified Specialist (Surgery and Neuro Surgery), ${ }^{+}$Senior Adviser (Medicine and Neurology), " Post Graduate Student (Surgery), Command Hosp (S.C), Pune 411040.
} 
Choroid Plexus Papilloma

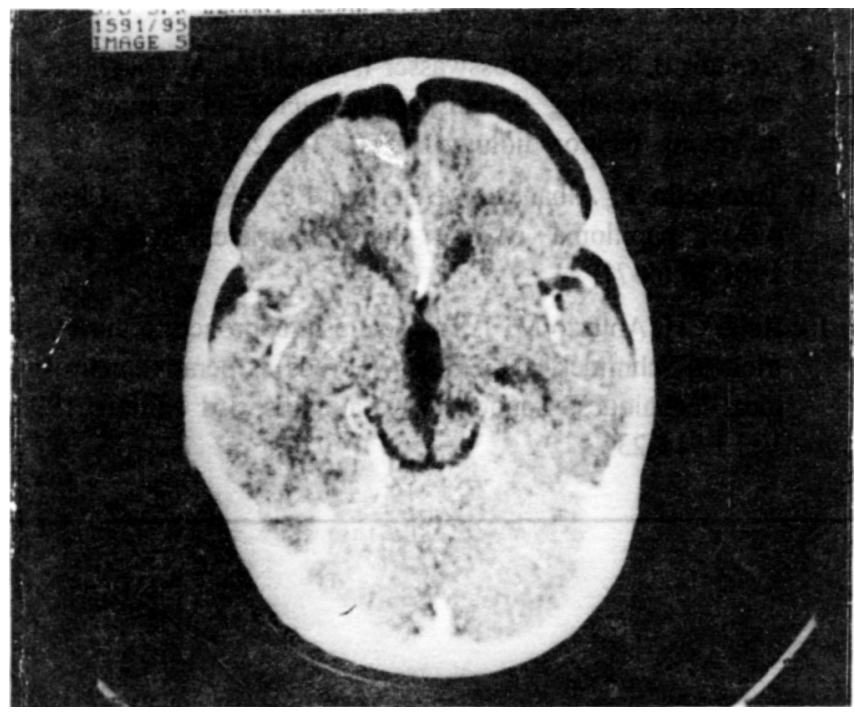

Fig. 3 : Post operative contrast enhanced scan showing total excision

in lateral ventricles, $39 \%$ in the fourth ventricle, $10 \%$ in third ventricle and $9 \%$ in the cerebellopontine angle [4]. The symptoms and signs of third ventricular papillomas are age dependent and secondary to hydrocephalus $[2,4,5]$. Hydrocephalus is caused by either mechanical obstruction of CSF flow or due to hypersecretion of CSF $[2,6]$. Although papillomas can occur in any age group, their greatest incidence is in the first two decades of life. The mean duration of symptoms is variable although symptoms in infants and children tend to be later in onset than in adults. Sudden death due to ventricular obstruction can also occur [3].

Though ultrasonography may detect third ventricular papillomas in infants and young children, Computerised Tomography scan is highly diagnostic and shows calcification on non contrast scan in $24 \%$, as was seen in our case. $75 \%$ of papillomas are isodense or hyperdense relative to brain parenchyma and $20 \%$ are hypodense or of mixed density. Tumour margin can be smooth $(29 \%)$, lobulated $(19 \%$, as was in our case) or irregular (52\%). Irregular margins are found both in malignant and benign papillomas [7]. On contrast enhanced Computerised Tomography scan papillomas enhance intensely $[7,8]$. Third ventricular choroid plexus papillomas are usually found in the anterior superior part of the third ventricle. However, in cases reporting late, they may occupy the whole of the third ventricle, as was seen in our case. The differential diagnosis of third ventricular tumours includes colloid cyst, meningioma, craniopharyngioma, glioma, ependymoma, dermoid, epidermoid and metastasis. Computerised Tomography scan features can exclude colloid cyst, meningioma, craniopharyngioma, dermoid and epidermoids [8]. In young patients like ours, metastasis is unlikely. Ependymomas have smaller in-

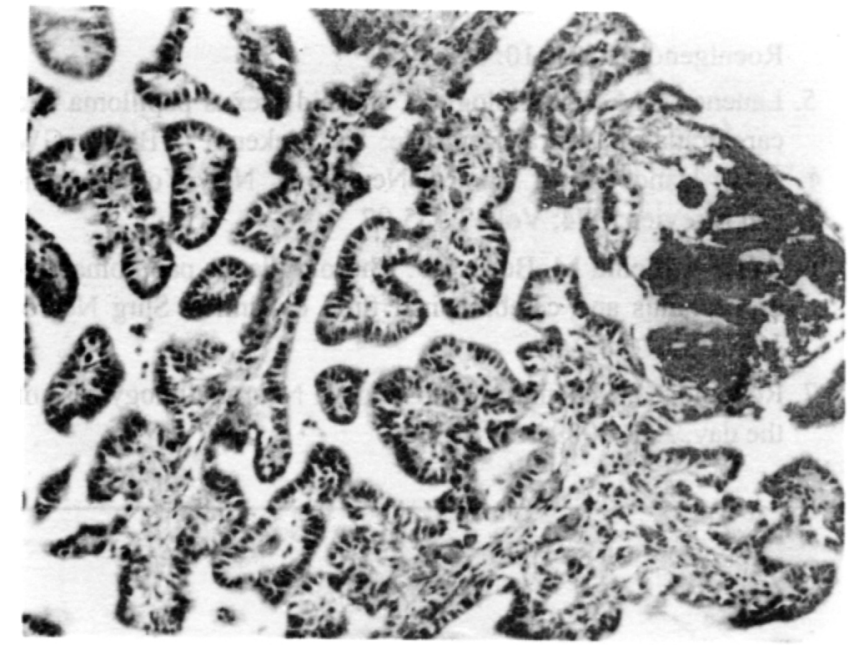

Fig. 4 : Histopathology : cuboidal epithelium on a fibrovascular tissue core and villous appearance ( $\mathrm{H} \& \mathrm{E}, 10 \mathrm{x})$

traventricular component and a larger component invading the adjacent parenchyma. Gliomas have considerable overlapping features with papillomas making reliable distinction difficult [7]. Angiography in such situations can be helpful as it will demonstrate tumour stain and well defined choroidal vessels in the case of papillomas [9]. It also helps in surgical planning. We could not do it in our case.

Third ventricular choroid plexus papillomas could be removed through transcallosal or transcortical approaches [9]. Interforniceal approach is required for larger lesions which cannot be removed through the foramen of Monro, as it provides wider access to the third ventricle [10].

$36 \%$ operative mortality rates have been reported for third ventricular choroid plexus papillomas. However, where total. excision was achieved it came down to $16 \%$ [9]. If these are not excised totally, they will recur [7] and therefore total excision is ideal. We used the interforniceal approach because it was a large lesion occupying the whole of the third ventricle and major part of tumour lying in the central and posterior parts of the third ventricle, the residual left sided hemiparesis is probably due to retraction injury to genu of internal capsule.

\section{REFERENCES}

1. Wilkins H, Rutledge BJ. Papillomas of choroid plexus. J Neurosurg 1961; 18: 14-8.

2. Matson DD, Crofton FD. Papilloma of the choroid plexus in childhood. J Neurosurg 1960; 17: 1002-27.

3. Gardin WC, Taylor C, Fruin AH. Choroid plexus papilloma of the third ventricle: Case report and review of literature. Neurosurgery 1983;12:217-20.

4. Rovit RL, Schechter MM, Chodroff P. Choroid plexus papillomas. Observation on radiographic diagnosis. Am J 
Roentgenol 1980; 110: 608-17.

5. Lauence KM. The biology of choroid plexus papilloma and carcinoma of lateral ventricle: In Vinken PJ, Bruyn GW (eds): Handbook of Clinical Neurology, New York. American Elsevier 1974; Vol.17;555-97.

6. Sahar A, Feind M, Beller AJ. Choroid plexus papilloma, hydrocephalus and cerebrospinal fluid dynamics. Surg Neurol 1980;13:476-8.

7. Romano AJ, Shoemaker El, Gado M. Neuroradiology case of the day. AJR 1989;152: 1333-5.
8. Kendell B, Reider-Grosswasser I, Valentine A. Diagnosis of masses presenting within the ventricles on computed tomography. Neuroradiology 1983;25:11-22.

9. Tomesello F, Albanese V, Bernini FP, Picozzi P. Choroid plexus papilloma of the third ventricle. Surg Neurol 1981;16:69-71.

10. Rabb CH, Apuzzo MLJ. Transcallosal approach to third ventricle in Schmidek HH, Sweet WH (eds). Operative neurosurgical techniques. London WB Saunders, 3rd edition, 1995; Vol.1:715-23 